\title{
Transaortic Transcatheter Aortic Valve Replacement in Patients From a Single Institution - Feasibility, Safety, and Midterm Outcomes -
}

\author{
Takashi Kakuta, MD; Satsuki Fukushima, MD, PhD; Naonori Kawamoto, MD, PhD; \\ Satoshi Kainuma, MD, PhD; Naoki Tadokoro, MD; Ayumi Ikuta, MD, PhD; \\ Kimito Minami, MD, PhD; Hideaki Kanzaki, MD, PhD; Makoto Amaki, MD, PhD; \\ Atsushi Okada, MD, PhD; Yuki Irie, MD; Kensuke Takagi, MD; \\ Chisato Izumi, MD, PhD; Tomoyuki Fujita, MD, PhD
}

\begin{abstract}
Background: Transaortic transcatheter aortic valve replacement (TAo-TAVR) is an alternative to peripheral or transapical TAVR. The procedural feasibility, safety, and midterm outcomes of TAo-TAVR were investigated in this study.

Methods and Results: Eighty-four consecutive patients underwent TAo-TAVR from 2011 to 2021 . Their median age was 83 years (interquartile range, 80-87 years). The Edwards SAPIEN and Medtronic CoreValve devices were used in 45 (53.6\%) and 38 (45.2\%) patients, respectively. The surgical approach was a right mini-thoracotomy in 43 patients $(51.2 \%)$ and partial sternotomy in 4 patients (4.8\%). The remaining 37 patients (44.0\%) underwent full sternotomy because of concomitant off-pump coronary artery bypass grafting. VARC-3 device success was achieved in 77 patients (91.7\%). Valve migration occurred in 3 patients (3.6\%) using a first-generation CoreValve device, necessitating implantation of a second valve. No aortic annulus rupture, aortic dissection, or coronary orifice occlusion occurred. Conversion to surgery was required for 1 patient because of uncontrollable bleeding. Only 1 in-hospital death occurred. New pacemaker implantation was required in 6 patients (7.1\%). Echocardiography at discharge showed no or trivial paravalvular leak (PVL) in 58 patients (69.0\%), mild PVL in 23 (27.4\%), and mild to moderate PVL in 2 (2.4\%) patients. The 1- and 3-year incidence of cardiovascular death was $1.6 \%$ and $4.8 \%$, respectively, with no structural valve deterioration.
\end{abstract}

Conclusions: TAo-TAVR is feasible and safe with satisfactory midterm outcomes using both currently available devices.

Key Words: Paravalvular leak; Right mini-thoracotomy; Transcatheter aortic valve replacement

$\mathbf{T}$ ranscatheter aortic valve replacement (TAVR) has evolved from an alternative to surgical aortic valve replacement (SAVR) for the treatment of aortic stenosis in patients with advanced age and comorbidities ${ }^{\mathbf{1 - 4}}$ to an established therapeutic alternative for the low-tointermediate risk population..$^{5-9}$ The transfemoral (TF) approach is the most common and safest route for TAVR. However, in up to $5-20 \%$ of patients screened for TFTAVR, access may be poor and an alternative access (e.g., trans-subclavian [TSc], transcarotid [TC], transapical [TA], or transaortic [TAo]) should be used. ${ }^{10-13}$

In the United States and Europe, TSc-TAVR is currently the preferred alternative access strategy when TF access is not feasible because it is reportedly associated with lower mortality or morbidity than TA-TAVR or
TAo-TAVR. ${ }^{14,15}$ TC-TAVR is also reportedly associated with a shorter length of hospital stay and lower mortality than TA-TAVR or TAo-TAVR. ${ }^{\mathbf{1 6}, 17}$ However, in Japanese patients who have a small physique, TSc-TAVR or TCTAVR is sometimes not feasible because the access vessel diameter in such patients is small $(<5 \mathrm{~mm})$. In these cases, TA or TAo access becomes essential as an alternative approach.

Our alternative TAVR started in 2011 with a TA approach, and we changed the fundamental alternative access strategy in our institution from TA to TAo in July 2018. The aim of this study was to evaluate the procedural feasibility, safety, and midterm outcomes of TAo-TAVR in an initial consecutive series of patients who underwent operations at a single institution.

Received October 15, 2021; revised manuscript received December 23, 2021; accepted December 25, 2021; J-STAGE Advance Publication released online February 5, 2022 Time for primary review: 16 days

Department of Cardiovascular Surgery (T.K., S.F., N.K., S.K., N.T., A.I., T.F.), Surgical Intensive Care (K.M.), Department of Cardiovascular Medicine (H.K., M.A., A.O., Y.I., K.T., C.I.), National Cerebral and Cardiovascular Research Center, Suita, Japan

Mailing address: Satsuki Fukushima, MD, PhD, Director, Department of Cardiac Surgery, National Cerebral and Cardiovascular Research Center, 6-1 Kishibe-Shinmachi, Suita 564-8565, Japan. E-mail: s.fukushima@ncvc.go.jp

All rights are reserved to the Japanese Circulation Society. For permissions, please e-mail: cj@j-circ.or.jp

ISSN-1346-9843 


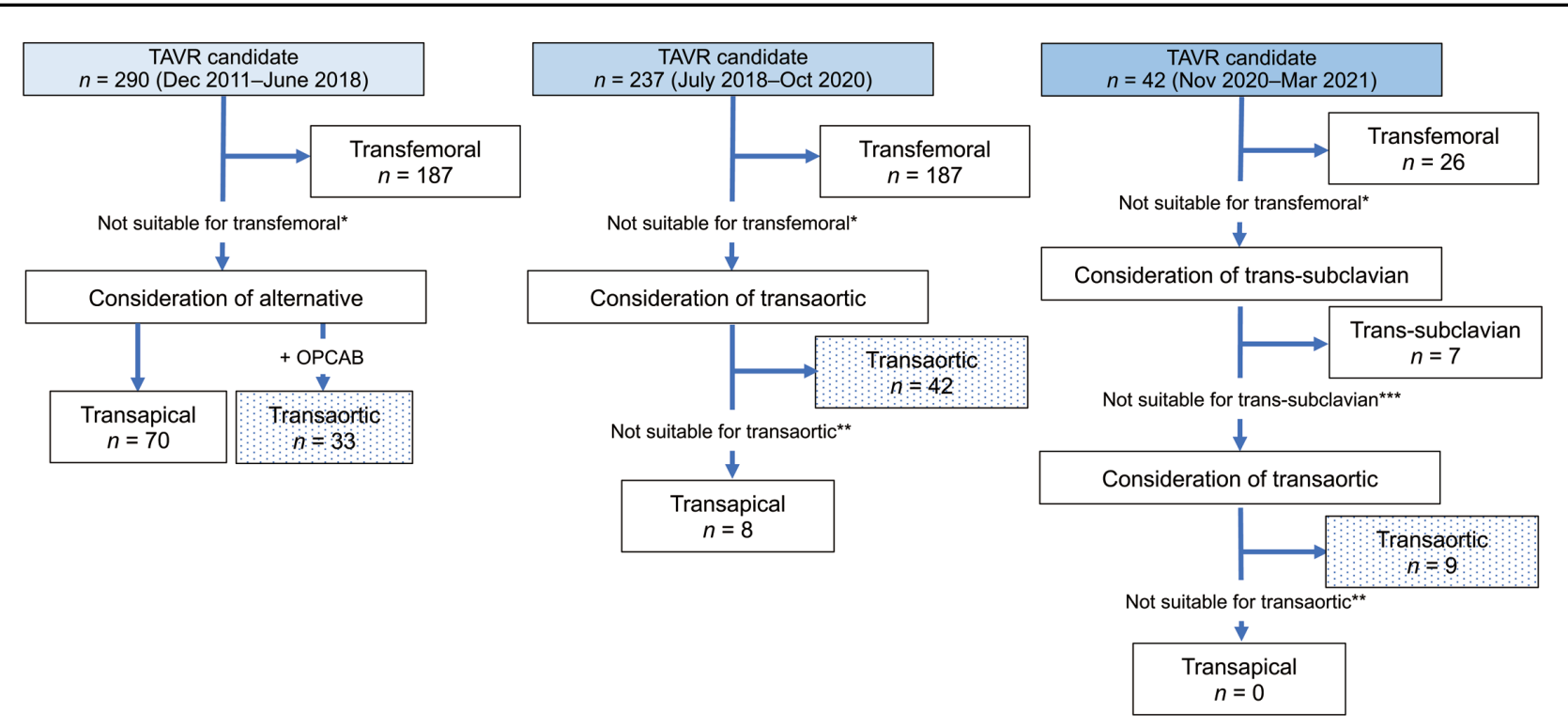

Figure 1. Algorithm to select candidates for transaortic transcatheter aortic valve replacement, stratified by surgical era. *Femo-

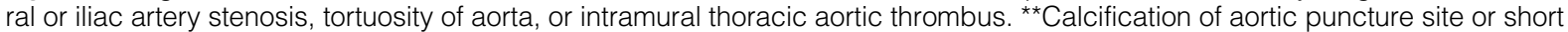
ascending aorta. ${ }^{* *}$ Left subclavian artery stenosis, tortuosity, or calcification. TAVR, transcatheter aortic valve replacement; OPCAB, off-pump coronary artery bypass grafting.
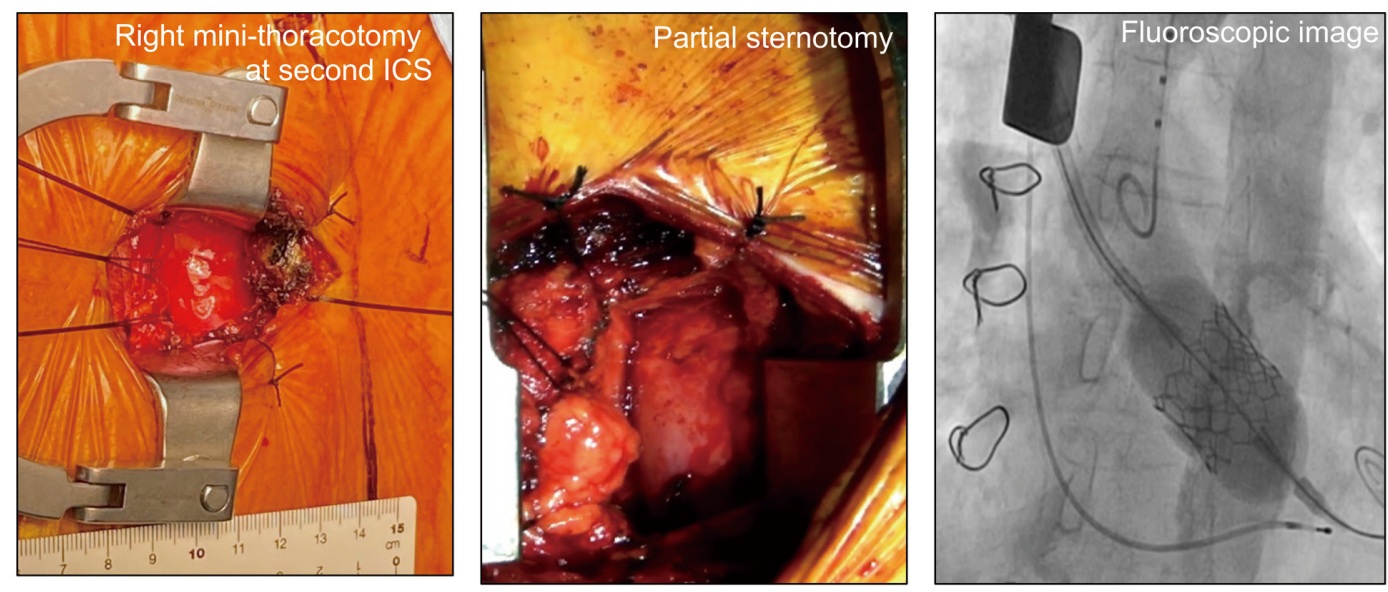

Figure 2. Surgical aortic view of transaortic transcatheter aortic valve replacement via right mini-thoracotomy at the second intercostal space and that of partial sternotomy. ICS, intercostal space.

\section{Methods}

\section{Study Cohort and Data Collection}

There were 569 patients who underwent TAVR in the National Cerebral and Cardiovascular Center Hospital from December 2011 to March 2021; the institutional surgical database contained a consecutive series of 84 patients who underwent TAo-TAVR. The data were retrospectively collected from the medical charts and operation reports. Data collection was performed in April 2021. Eighty patients $(95.2 \%)$ completed follow up, but 4 patients $(4.8 \%)$ could not be contacted and were therefore defined as "lost to follow up." Prior to the surgery, all patients gave written informed consent for surgery and for the use of their data and samples for diagnostic and research purposes. The data collection, analysis, and reporting were approved by the National Cerebral and Cardiovascular Center Institutional Review Board (reference number: M30-026) and were in accordance with the Declaration of Helsinki and the ethical standards of our institutional committee on human experimentation.

\section{Indications for TAO-TAVR}

The surgical indications for TAVR were discussed by the 


\begin{tabular}{|c|c|}
\hline \multicolumn{2}{|l|}{ Variables } \\
\hline Number of patients & $84(100)$ \\
\hline Age, years & $83(80-87)$ \\
\hline $\mathrm{BSA}, \mathrm{m}^{2}$ & $1.4(1.3-1.6)$ \\
\hline Male sex & $31(36.9)$ \\
\hline \multicolumn{2}{|l|}{ Preoperative echocardiography } \\
\hline LVEF, \% & $63(57-67)$ \\
\hline LVDD, mm & $57(53-60)$ \\
\hline LVDS, mm & $36(31-39)$ \\
\hline Aortic valve area, $\mathrm{cm}^{2}$ & $0.7(0.6-0.9)$ \\
\hline MPG & $46(39-54)$ \\
\hline Bicuspid aortic valve & $3(3.6)$ \\
\hline \multicolumn{2}{|l|}{ AR grade } \\
\hline None & $5(5.9)$ \\
\hline Trivial & $46(54.8)$ \\
\hline Mild & $26(31.0)$ \\
\hline$>$ Moderate & 7 (8.3) \\
\hline MR grade $>$ moderate & $4(4.8)$ \\
\hline MS grade $>$ moderate & $3(3.6)$ \\
\hline TR grade $>$ moderate & $6(7.1)$ \\
\hline \multicolumn{2}{|l|}{ Preoperative CT } \\
\hline Aortic annulus diameter, $\mathrm{mm}$ & $23(21-24)$ \\
\hline Aortic annulus area, $\mathrm{mm}^{2}$ & $399(360-446)$ \\
\hline Aortic annulus perimeter, $\mathrm{mm}$ & $72(68-76)$ \\
\hline Valsalva sinus diameter, mm & $29(27-32)$ \\
\hline ST junction diameter, mm & $26(24-28)$ \\
\hline Angle of aortic valve, degrees & $51(45-57)$ \\
\hline
\end{tabular}

(Table 1 continued the next column.)

institutional heart team comprising cardiologists, radiologists, and surgeons, with primary reference to published guidelines. ${ }^{18}$ Electrocardiography-gated multidetector computed tomography (Somatom Definition Flash; Siemens Healthcare, Erlangen, Germany) was performed prior to TAVR to determine the appropriate use of the SAPIEN (Edwards Lifesciences, Irvine, CA, USA) or CoreValve (Medtronic, Minneapolis, MN, USA) transcatheter heart valve (THV), as well as the appropriate access site. If the patient did not have a suitable femoral or subclavian anatomy, we then preceded with a TAo approach. Finally, candidates for TAo-TAVR were selected by the institutional algorithm, as shown in Figure 1.

\section{Procedure of TAO-TAVR}

The patients were placed under general anesthesia and underwent endotracheal intubation. A right-heart catheter with a pacemaker (Harmac Medical Products, Inc., Buffalo, NY, USA) was inserted via the right jugular vein in all patients. A right mini-thoracotomy at the second intercostal space was performed through a 4 - to 5 -cm skin incision in 43 patients (51.2\%), as shown in Figure 2 and Supplementary Movie. Upper partial sternotomy was required in 4 patients $(4.8 \%)$ because of the left-sided location or shortness of their ascending aorta. A simultaneous TAo-TAVR and off-pump coronary artery bypass grafting $(\mathrm{OPCAB})$ procedure following median full sternotomy was performed in 37 patients $(44.0 \%)$ in keeping with our institutional strategy for high-risk patients with proximal left anterior descending artery (LAD) lesions and/or high SYNTAX

\begin{tabular}{|c|c|}
\hline \multicolumn{2}{|l|}{ Variables } \\
\hline \multicolumn{2}{|l|}{ Indication for alternative approach } \\
\hline Shaggy aorta & $30(35.7)$ \\
\hline Tortuous aorta & $13(15.5)$ \\
\hline Abdominal aortic aneurysm & $9(10.7)$ \\
\hline Thoracic aortic aneurysm & $5(6.0)$ \\
\hline Iliac or femoral artery stenosis & 33 (39.3) \\
\hline \multicolumn{2}{|l|}{ Conduction disturbances } \\
\hline First-degree AVB & $5(6.0)$ \\
\hline Second-degree AVB & $1(1.2)$ \\
\hline Complete AVB after PMI & $3(3.6)$ \\
\hline Left bundle branch block & $3(3.6)$ \\
\hline Right bundle branch brunch & $6(7.1)$ \\
\hline \multicolumn{2}{|l|}{ Atrial fibrillation } \\
\hline Paroxysmal & $8(9.5)$ \\
\hline Non-paroxysmal & $7(8.3)$ \\
\hline Previous cardiac surgery & $12(14.3)$ \\
\hline Preoperative cardiogenic shock & $1(1.2)$ \\
\hline \multicolumn{2}{|l|}{ Non-cardiac comorbidities } \\
\hline Hypertension & $72(85.7)$ \\
\hline Hypercholesterolemia & $49(58.3)$ \\
\hline Diabetes mellitus & $20(23.8)$ \\
\hline Coronary artery disease & $61(72.6)$ \\
\hline COPD (FEV1.0\% <70\%) & $15(17.9)$ \\
\hline Renal dysfunction $(\mathrm{Cr}>1.5)$ & $6(7.1)$ \\
\hline Clinical frailty scale & $4(3-4)$ \\
\hline STS PROM score & $6.6(4.7-9.9)$ \\
\hline
\end{tabular}

Continuous variables are presented as median (interquartile range), and categorical variables are presented as number (\%). $A R$, aortic regurgitation; $A V B$, atrioventricular block; $B S A$, body surface area; COPD, chronic obstructive pulmonary disease; $\mathrm{Cr}$, serum creatinine level; CT, computed tomography; FEV, forced expiratory volume; LVDD, left ventricular diastolic diameter; LVDS, left ventricular systolic diameter; LVEF, left ventricular ejection fraction; MPG, mean pressure gradient across aortic valve; MR, mitral regurgitation; MS, mitral stenosis; PMI, pacemaker implantation; ST junction, sinotubular junction; STS PROM, Society of Thoracic Surgeons Predicted Risk of Mortality; TR, tricuspid regurgitation.

score, as previously reported. ${ }^{19}$ The pericardium was opened and suspended. Two aortic purse string sutures were placed, as per standard aortic cannulation for cardiopulmonary bypass. A 5-Fr sheath was inserted from the right radial artery, and a marker pigtail catheter was then placed on the bottom of the Valsalva sinus for injection of contrast medium. The sufficient distance between the aortic annulus and aortic puncture site (SAPIEN, $>5.5 \mathrm{~cm}$; CoreValve, $>6.0 \mathrm{~cm}$ ) was confirmed by contrast medium injection and the marker pigtail catheter. A 5-Fr short sheath was inserted in the ascending aorta and the aortic valve was crossed with a straight guidewire, allowing the subsequent introduction of an extra-stiff Amplatz guidewire (Boston Scientific, Marlborough, MA, USA) or, more recently, a preshaped Safari guidewire (Boston Scientific) to reduce the risk of left ventricular (LV) perforation. The need for predilatation was determined preoperatively by the heart team. A balloon-expandable device was deployed under rapid pacing with 150 to 200 beats/min, whereas a self-expandable device was gradually deployed with stepwise angiographical guidance without rapid pacing. The need for postdilatation was discussed for patients with an 


\begin{tabular}{|c|c|}
\hline Variables & \\
\hline \multicolumn{2}{|l|}{ THV type } \\
\hline SAPIEN XT & $12(14.3)$ \\
\hline SAPIEN 3 & $33(39.3)$ \\
\hline CoreValve & $18(21.4)$ \\
\hline CoreValve Evolut R & $13(15.5)$ \\
\hline CoreValve Evolut PRO & $3(3.6)$ \\
\hline CoreValve Evolut PRO+ & $4(4.8)$ \\
\hline \multicolumn{2}{|l|}{ THV size } \\
\hline \multicolumn{2}{|l|}{ SAPIEN series } \\
\hline 20 & $2(2.4)$ \\
\hline 23 & $24(28.9)$ \\
\hline 26 & $15(18.1)$ \\
\hline 29 & $3(3.6)$ \\
\hline \multicolumn{2}{|l|}{ CoreValve/Evolut series } \\
\hline 23 & $6(7.2)$ \\
\hline 26 & $19(22.9)$ \\
\hline 29 & $11(13.3)$ \\
\hline 34 & $3(3.6)$ \\
\hline \multicolumn{2}{|l|}{ Approach } \\
\hline Right mini-thoracotomy & $43(51.2)$ \\
\hline Upper partial sternotomy & $4(4.8)$ \\
\hline Full sternotomy (TAo-TAVR+OPCAB) & $37(44.0)$ \\
\hline TAV-in-SAV procedure & $3(3.6)$ \\
\hline VARC-3 device success & $77(91.7)$ \\
\hline Valve migration & $3(3.6)$ \\
\hline $\begin{array}{l}\text { Unplanned use of mechanical circulatory } \\
\text { support }\end{array}$ & $1(1.2)$ \\
\hline Conversion to full sternotomy & $1(1.2)$ \\
\hline Conversion to SAVR & $1(1.2)$ \\
\hline Pre-dilatation & $24(28.6)$ \\
\hline Post-dilatation & $15(17.9)$ \\
\hline \multicolumn{2}{|l|}{ Operation time, $\min$} \\
\hline TAo-TAVR & $117(102-133)$ \\
\hline TAo-TAVR+OPCAB & $271(247-316)$ \\
\hline \multicolumn{2}{|l|}{ Intraoperative complications } \\
\hline Aortic annulus rupture & $0(0.0)$ \\
\hline Aortic injury & $1(1.2)$ \\
\hline Aortic dissection & $0(0.0)$ \\
\hline LM occlusion & $0(0.0)$ \\
\hline \multicolumn{2}{|l|}{ Blood transfusion } \\
\hline TAo-TAVR & $40(85.1)$ \\
\hline TAo-TAVR + OPCAB & $37(100)$ \\
\hline
\end{tabular}

Continuous variables are presented as median (interquartile range), and categorical variables are presented as number (\%). LM, left main trunk; OPCAB, off-pump coronary artery bypass grafting; SAVR, surgical aortic valve replacement; TAo-TAVR, transaortic transcatheter aortic valve replacement; TAV-in-SAV, transcatheter aortic valve in surgical aortic valve; THV, transcatheter heart valve; VARC-3, Valve Academic Research Consortium 3.

intraoperative paravalvular leak (PVL) depending on its degree and nature, as shown by intraoperative transesophageal echocardiography. A final angiographic projection was performed in all patients, and the PVL from the THV and the coronary orifice stenosis were evaluated. Device success was defined based on the updated Valve Academic Research Consortium 3 (VARC-3) definitions, which include the technical success, freedom from mortality or re-intervention related to the procedure, and fulfillment of the intended performance of the THV. ${ }^{20}$

\section{Postoperative Care}

All patients were transferred postoperatively to the intensive care unit (ICU). Postoperative electrocardiography was performed on ICU admission and on days 1, 2, and 7 days post-TAVR. Telemetry monitoring was continued for at least 5 days postoperatively in all patients to detect atrioventricular block (AVB). Permanent pacemaker implantation was indicated in patients with complete AVB or repeated temporal AVB with syncope following TAVR under approval following discussion with the heart team.

Single antiplatelet therapy consisting of $100 \mathrm{mg}$ of aspirin or $75 \mathrm{mg}$ of clopidogrel was administered postoperatively to 42 patients $(50.0 \%)$, and dual antiplatelet therapy using both drugs at the above described doses was administered postoperatively to 8 patients $(9.5 \%)$. Warfarin or a non-vitamin $\mathrm{K}$ antagonist oral anticoagulant was administered to the remaining 34 patients $(40.5 \%)$.

\section{Echocardiography}

All patients were examined by standard transthoracic echocardiography within 2 weeks preoperatively and within 1 week postoperatively in accordance with the routine clinical practice guidelines of our institute. Standard data, including the LV ejection fraction (LVEF), LV systolic and diastolic dimensions (LVSD and LVDD, respectively), effective orifice area (EOA), and presence of a PVL, were obtained from the institutional echocardiographic report. The indexed EOA was calculated as the EOA divided by the body surface area.

\section{Statistical Analysis}

The categorical data in Table $\mathbf{1}$ are presented as number $(\%)$. Continuous data were presented as median and interquartile range (IQR). A competing risk model was used to assess the incidence of cardiovascular death or cerebrovascular accidents. Cardiovascular death was defined based on the updated VARC-3 definitions, which include death related to heart failure, cardiogenic shock, bioprosthetic valve dysfunction, myocardial infarction, stroke, thromboembolism, vascular complication, arrhythmia, cardiovascular infection, sudden death, or unknown death. ${ }^{19}$ All statistical analyses were performed using statistical software (R v4.0.3; The R Foundation for Statistical Computing, Vienna, Austria).

\section{Results}

\section{Baseline Characteristics}

A total of 92 patients were initially considered for TAoTAVR, but 8 patients (8.7\%) were judged not suitable by heart team discussion because of their calcification of aortic puncture site; therefore, the remaining 84 patients underwent TAo-TAVR during the study period (Figure 1). Baseline patient characteristics and preoperative echocardiography and computed tomography data in the study population are shown in Table 1. Patient median age was 83 years (IQR: $80-87$ years). The median aortic valve area and aortic mean pressure gradient were $0.7 \mathrm{~cm}^{2}$ (IQR: $0.6-$ $0.9 \mathrm{~cm}^{2}$ ) and $46 \mathrm{mmHg}$ (IQR: $39-54 \mathrm{mmHg}$ ), respectively. Severe peripheral artery stenosis was evident in 33 patients $(39.3 \%)$, whereas the remaining patients were judged unsuitable for TF-TAVR because of a shaggy aorta in 30 


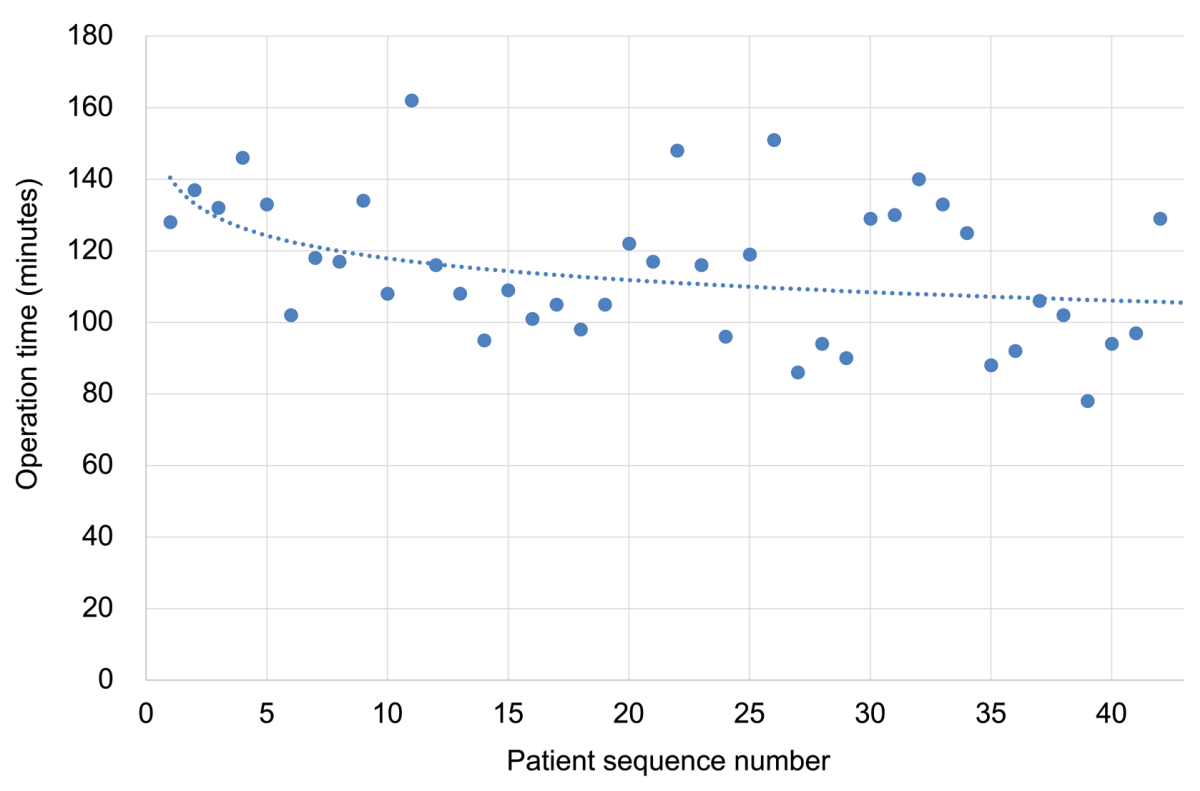

Figure 3. Patient sequence number and operation time showing learning curve for transaortic transcatheter aortic valve replacement via right mini-thoracotomy approach.

$(35.7 \%)$, tortuous aorta in $13(15.5 \%)$, abdominal aortic aneurysm in $9(10.7 \%)$, and thoracic aortic aneurysm in 5 $(6.0 \%)$. All patients presented with preoperative intermediate or high surgical risk, with a median Society of Thoracic Surgeons Predicted Risk of Mortality (STS PROM) score of 6.6 (IQR: 4.7-9.9) and clinical frailty scale score of 4 (IQR: 3-4).

\section{Procedural Details}

The procedural details are presented in Table 2. TAoTAVR with the SAPIEN valve series was performed in 45 patients $(53.6 \%)$, whereas TAo-TAVR with the CoreValve series was performed in 38 patients $(45.2 \%)$. The median size of the THV was $26 \mathrm{~mm}$ (IQR: 23-26 mm). The median distance between the aortic annulus and planned aortic puncture site was $7.5 \mathrm{~cm}$ (IQR: $7.0-8.0 \mathrm{~cm}$, range: $5.1-$ $9.5 \mathrm{~cm}$ ) on preoperative CT, and $7.0 \mathrm{~cm}$ (IQR: $7.0-8.0 \mathrm{~cm}$, range: $5.5-10.0 \mathrm{~cm}$ ) on intraoperative measurement using a marker pigtail catheter. Regarding the surgical approach, a right mini-thoracotomy was selected in 43 patients $(51.2 \%)$, whereas the median full sternotomy was chosen in 37 patients $(44.0 \%)$ according to the need for surgical myocardial revascularization through OPCAB grafting. In the cases requiring $\mathrm{OPCAB}$ grafting, left internal thoracic artery (LITA) was first anastomosed to the LAD before TAo-TAVR. In 24 cases $(28.9 \%)$ requiring revascularization of the diagonal, circumflex, and right coronary branches, OPCAB grafting using a composite radial artery graft anastomosed to the side of the LITA was performed after completion of both the LITA to LAD anastomosis and TAo-TAVR. The median number of distal anastomoses was 2 (IQR: 1-3, range: $1-4$ ). After elevation of the LV apex for anastomosis, there were no cases of malpositioning of the THV. The TAV-in-SAV procedure was performed in 3 patients $(3.6 \%)$. The proportion of cases requiring blood transfusion was as high as $85.1 \%$ in patients who only underwent the TAo-TAVR procedure (40/47) and $100 \%$ in those who underwent the simultaneous TAo-TAVR and OPCAB procedure (36/36).

\section{Feasibility and Safety of TAo-TAVR}

In-hospital outcomes are shown in Table 2. VARC-3 device success was achieved in 77 patients $(91.7 \%)$. Valve migration occurred in 3 patients $(3.6 \%)$ who underwent TAo-TAVR using the first-generation CoreValve device, which led to the need to implant a second valve. No aortic annulus rupture occurred; however, conversion to SAVR under median full sternotomy was performed in 1 patient because of massive bleeding from the ascending aorta after 22-Fr sheath insertion. No aortic dissection or coronary orifice occlusion occurred. Only $1(1.2 \%)$ in-hospital death occurred, caused by multiple organ failure due to preoperative cardiogenic shock requiring resuscitation and extracorporeal mechanical support. With respect to postoperative complications, new pacemaker implantation occurred in 6 patients $(7.1 \%)$, cardiac tamponade in 3 patients $(3.6 \%)$, pleural cavity bleeding requiring reoperation in 2 patients $(2.4 \%)$, in-hospital stroke in 2 patients $(2.4 \%)$, acute kidney injury requiring new hemodialysis in 3 patients $(3.6 \%)$, and respiratory failure in 2 patients $(2.4 \%)$. The median ICU length of stay and hospital length of stay were 3 days (IQR: 3-4 days) and 12 days (IQR: $10-13$ days), respectively. Sixty-five patients $(77.4 \%)$ were able to be discharged to their home. Unplanned extension of the ICU stay by more than 1 week occurred for 4 patients $(4.8 \%)$, including 2 with cardiac tamponade and 2 with acute renal failure requiring hemodialysis.

\section{Good Functionality of THV After TAo-TAVR}

Postoperative transthoracic echocardiography showed no or trivial PVL in 58 patients $(69.0 \%)$, mild PVL in 23 $(27.4 \%)$, and mild-to-moderate PVL in $2(2.4 \%)$ patients. 


\begin{tabular}{|c|c|}
\hline \multicolumn{2}{|l|}{ Variables } \\
\hline Early death, in-hospital or 30-day & $1(1.2)$ \\
\hline Re-surgical intervention & $0(0.0)$ \\
\hline ICU length of stay, days & $3(3-4)$ \\
\hline Hospital length of stay, days & $12(10-13)$ \\
\hline Discharge to home & $65(77.4)$ \\
\hline \multicolumn{2}{|l|}{ Postoperative complications } \\
\hline $\mathrm{Ml}<72 \mathrm{~h}$ & $0(0.0)$ \\
\hline New pacemaker implantation & $6(7.1)$ \\
\hline Cardiac tamponade & $3(3.6)$ \\
\hline Pleural cavity bleeding & $2(2.4)$ \\
\hline In-hospital cerebrovascular events & $2(2.4)$ \\
\hline Distal embolization & $0(0.0)$ \\
\hline $\begin{array}{l}\text { Acute kidney injury requiring } \\
\text { hemodialysis }\end{array}$ & $3(3.6)$ \\
\hline Deep infection & $0(0.0)$ \\
\hline Infective endocarditis & $0(0.0)$ \\
\hline Bacteremia & $2(2.4)$ \\
\hline Respiratory failure & $2(2.4)$ \\
\hline \multicolumn{2}{|l|}{ Echocardiography 1 week postoperatively } \\
\hline LVEF, \% & $57(50-62)$ \\
\hline LVDD, mm & $43(40-49)$ \\
\hline LVDS, mm & $29(26-34)$ \\
\hline $\mathrm{EOA}, \mathrm{cm}^{2}$ & $1.67(1.47-1.95)$ \\
\hline $\mathrm{EOAi}, \mathrm{cm}^{2} / \mathrm{m}^{2}$ & $1.10(0.97-1.30)$ \\
\hline Moderate PPM $\left(\mathrm{EOAi}<0.85 \mathrm{~cm}^{2} / \mathrm{m}^{2}\right)$ & $2(2.4)$ \\
\hline Severe PPM $\left(E O A i<0.65 \mathrm{~cm}^{2} / \mathrm{m}^{2}\right)$ & $0(0.0)$ \\
\hline MPG, mmHg & $10(8-12)$ \\
\hline$>20 \mathrm{mmHg}$ & $2(2.4)$ \\
\hline \multicolumn{2}{|l|}{ PVL grade } \\
\hline None & $23(27.4)$ \\
\hline Trivial & $35(41.7)$ \\
\hline Mild & $23(27.4)$ \\
\hline Mild to moderate & $2(2.4)$ \\
\hline
\end{tabular}

Continuous variables are presented as median (interquartile range), and categorical variables are presented as number (\%). $E O A$, effective orifice area; EOAi, indexed effective orifice area; ICU, intensive care unit; MI, myocardial ischemia; PPM, prosthesis-patient mismatch; PVL, perivalvular leak. Other abbreviations as in Table 1.

No patients had PVL of more than a moderate grade. The median pressure gradient across the aortic valve was $10 \mathrm{mmHg}$ (IQR: 8-12 mmHg), and the indexed EOA was 1.10 (IQR: 0.97-1.30). Moderate prosthesis-patient mismatch was observed in 2 patients, and no patients had severe prosthesis-patient mismatch. The postoperative LVEF, LVDD, and LVDS was 57\% (IQR: 50-62\%), $43 \mathrm{~mm}$ (IQR: $40-49 \mathrm{~mm}$ ), and $29 \mathrm{~mm}$ (IQR: 26-34 mm), respectively.

\section{Minimal Learning Curve for TA0-TAVR}

The median operation times for patients who underwent only TAo-TAVR and TAo-TAVR with OPCAB were $117 \mathrm{~min}$ (IQR: 102-133 $\mathrm{min}$ ) and $271 \mathrm{~min}$ (IQR: 247-316 min), respectively. The learning curve with respect to the operation time of TAo-TAVR via right mini-thoracotomy is shown in Figure 3; the operation time slightly decreased until the first 10 cases were completed and then plateaued approximately between 100 and $120 \mathrm{~min}$, except in certain cases.

\section{Midterm Outcomes After TAo-TAVR}

The median follow-up duration was 1.5 years (IQR: 0.4 3.4 years). All-cause death occurred in 7 patients $(8.4 \%)$ during follow up, whereas cardiovascular death occurred in 3 patients $(3.6 \%)$ (Table 3$)$. The cumulative incidence of cardiovascular death with non-cardiovascular death as the competing risk at 1 year and 3 years was $1.6 \%$ (95\% confidence interval [CI]: 0.1-7.6) and 4.8\% (95\% CI: 0.7-15.2), respectively (Figure 4), whereas that of cerebrovascular accidents with all-cause death as the competing risk at 1 year and 3 years was $4.1 \%(95 \%$ CI: $1.1-10.7)$ and $4.1 \%$ (95\% CI: 1.1-10.7), respectively (Figure 4). During follow up, re-hospitalization occurred in 16 patients $(19.3 \%)$, including procedure-related hospitalization in $3(3.6 \%)$, valve-related hospitalization in $1(1.2 \%)$, other cardiovascular hospitalization in $6(7.2 \%)$, and non-cardiovascular hospitalization in $6(7.2 \%)$ patients (Table 4). The causes of procedure-related hospitalization were right pleural effusion requiring drainage in 2 patients and a second rib fracture leading to sequestration requiring debridement in 1 patient. The only cause of valve-related hospitalization was infective endocarditis without the need for an additional aortic valve procedure. No patients developed structural valve deterioration or prosthetic valve thrombosis. Non-cardiovascular hospitalization included cerebral bleeding in 2 patients, but no stroke occurred during outpatient follow up in this cohort.

\section{Discussion}

The present study revealed the early and midterm outcomes of the first 84 consecutive patients with aortic stenosis who underwent TAo-TAVR in our institution. VARC-3 valve success was accomplished in 77 patients $(91.7 \%)$, and 72 patients $(85.7 \%)$ had no complications related to the surgery. Only $1(1.2 \%)$ in-hospital death occurred in this cohort. Regarding valve or cardiac function, 81 patients (96.4\%) showed no to mild PVL with preserved valve or cardiac function at the time of hospital discharge. Midterm outcomes showed low cardiovascular mortality and a low incidence of procedure- or valve-related rehospitalization. The results in this study are considerably more favorable than recent reports showing a 30-day mortality of 5.0$11.3 \%$ and a 1 -year mortality of $15.3-30.3 \% .^{21,22}$

Although several large registries failed to find significant differences in both early and late mortality between TAo and TA approaches, ${ }^{14,23}$ TAo-TAVR is considered to be a valid and effective surgical alternative to TA-TAVR because of the following reasons: (1) no contact with or suturing of the LV myocardium leading to preservation of $\mathrm{LV}$ cardiac function ${ }^{24,25}$ or avoidance of LV false aneurysm;26-28 (2) the ability to use both the SAPIEN and CoreValve devices; (3) minimal risk of aortic plaque embolization because of no guidewire manipulation of the aortic arch and supra-aortic vessels; and (4) the smooth learning curve associated with the aortic manipulation, which are part of daily practice in cardiac surgery..$^{29,30}$ Therefore, we changed the fundamental strategy of alternative access in our institution from TA to TAo in July 2018, and the number of TAo approaches proportionally increased from $5.1 \%$ (4/79) in 2017 to $17.8 \%$ $(18 / 101)$ in 2020 . Additionally, the TC approach was initi- 


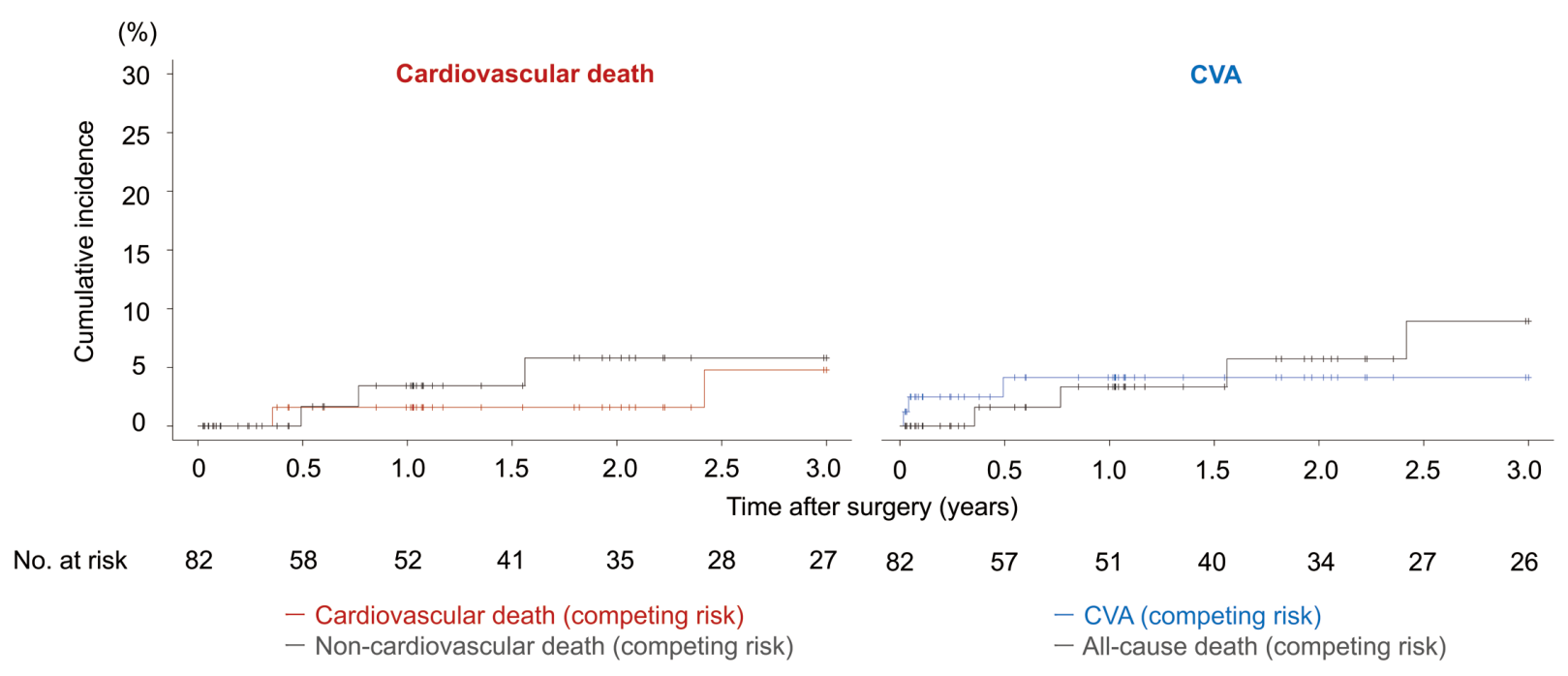

Figure 4. Cumulative incidence plot of cardiovascular death with non-cardiovascular death as a competing risk and that of cerebrovascular accidents with all-cause death as a competing risk. CVA, cerebrovascular accidents.

ated in November 2020 in our institution; however, the TAo approach was still used in $21.4 \%(9 / 42)$ of recent cases, as shown in Figure 1.

The most important key to safe performance of TAoTAVR is patient selection by preoperative computed tomography imaging. The TAo approach is not suitable for patients with a fragile or calcified ascending aorta. In fact, TAo-TAVR was deferred for 8 patients $(8.7 \%)$ because of calcification of aortic puncture site during the study period. However, 1 patient in our series required conversion to SAVR because of uncontrollable bleeding from the fragile ascending aorta. A recent large registry showed that the percentage of aortic access complications (e.g., dissection, rupture, or uncontrollable bleeding) and rate of conversion to SAVR after TAo-TAVR was $2.0 \%{ }^{31}$ and $1.7-2.8 \%, 23,31$ respectively. Regarding postoperative bleeding complications, the percentage of cases with life-threatening bleeding was $8.3 \%$ in cases of TA-TAVR and $3.4 \%$ in cases of TAoTAVR. ${ }^{22}$ In our cohort, there was no aortic puncture siterelated postoperative bleeding; however, postoperative hemothorax due to oozing blood from intercostal or pectoralis muscle occurred in a 97-year-old man with high frailty and an 87-year-old woman receiving oral anticoagulation therapy. Postoperative cardiac tamponade with serous fluid retention occurred in 3 patients with advanced stage renal failure who underwent TAo-TAVR via right mini-thoracotomy. To prevent this complication, pericardial drain tube placement was performed in all recent cases. We believe that proper patient selection and understanding these pitfalls of TAo-TAVR are important for the satisfactory results of this procedure.

Regarding the surgical approach, there are 4 approaches to expose the ascending aorta: full sternotomy, upper partial sternotomy, manubriotomy, ${ }^{27}$ or right mini-thoracotomy. Right mini-thoracotomy is considered a less invasive approach, but it is not suitable for patients whose ascending aorta is located toward the left side because the distance to the device insertion site is too far. Similarly, preoperative measurement to ensure sufficient distance

\begin{tabular}{|c|c|}
\hline \multicolumn{2}{|c|}{$\begin{array}{l}\text { Table 4. Mid-Term Outcomes After Transaortic } \\
\text { Transcatheter Aortic Valve Replacement }\end{array}$} \\
\hline Variables & \\
\hline Follow-up period, years & $1.5(0.4-3.4)$ \\
\hline All-cause mortality at follow up & $7(8.4)$ \\
\hline Cardiovascular mortality at follow up & $3(3.6)$ \\
\hline Non-cardiovascular mortality at follow up & $4(4.8)$ \\
\hline Re-hospitalization & $16(19.3)$ \\
\hline Procedure-related hospitalization & $3(3.6)$ \\
\hline Valve-related hospitalization & $1(1.2)$ \\
\hline Other cardiovascular hospitalization & $6(7.2)$ \\
\hline Non-cardiovascular hospitalization & $6(7.2)$ \\
\hline Bioprosthetic valve dysfunction & $1(1.2)$ \\
\hline Structural valve deterioration & $0(0.0)$ \\
\hline Thrombosis & $0(0.0)$ \\
\hline Endocarditis & $1(1.2)$ \\
\hline
\end{tabular}

Continuous variables are presented as median (interquartile range), and categorical variables are presented as number (\%).

between the aortic annulus and planned aortic puncture site is also crucial for the right mini-thoracotomy approach, especially in patients with a small physique. This is because the SAPIEN and the CoreValve device require a distance of $>5.5 \mathrm{~cm}$ and $6.0 \mathrm{~cm}$, respectively, for successful deployment of their valves. In our cohort, the median distance was $7.5 \mathrm{~cm}$ (IQR: $7.0-8.0 \mathrm{~cm}$, range: $5.1-9.5 \mathrm{~cm}$ ) on preoperative CT, and $7.0 \mathrm{~cm}$ (IQR: $7.0-8.0 \mathrm{~cm}$, range: $5.5-10.0 \mathrm{~cm}$ ) on intraoperative measurement using a marker pigtail catheter. The distances measured using both methods were similar. In the patient with the shortest distance $(5.1 \mathrm{~cm})$ on preoperative CT, TAo-TAVR with upper partial sternotomy was selected rather than intercostal thoracotomy to perform a safer operation. The learning curve of TAoTAVR via right mini-thoracotomy, as assessed by the time taken to complete the procedure, is not substantial, espe- 
cially for surgeons with experience in valve surgery via the right thoracotomy approach.

Regarding the optimal bypass graft design in simultaneous TAo-TAVR and OPCAB procedure, the rationale behind our avoidance of aorto-conduit anastomosis is that aortic side clamping as a bailout from uncontrollable bleeding at the aortic anastomosis site becomes impossible after the TAVR procedure, especially when using the CoreValve series THV. In addition, elderly patients who are indicated for TAo-TAVR often have a fragile and arteriosclerotic aorta, and it is advantageous to avoid aortic anastomosis to prevent additional surgical bleeding or cerebral infarction. Although revascularization using bilateral ITA is also a good option in these cases, our strategy was to mainly use a composite radial artery graft anastomosed to the side of the LITA to prevent postoperative protracted sternal healing or mediastinitis in the elderly patients.

\section{Conclusions}

The TAo-TAVR procedure was feasible, safe, and therapeutically effective even in the first 84 cases. The important keys to safe performance of TAo-TAVR are proper patient selection and understanding its pitfalls. This approach will contribute to further development of alternative TAVR procedures, especially in small Japanese patients.

\section{Acknowledgment}

We thank Angela Morben, DVM, ELS, from Edanz (https://jp.edanz. $\mathrm{com} / \mathrm{ac}$ ) for editing a draft of this manuscript.

\section{Sources of Funding}

No funding was obtained for this work.

\section{Disclosures}

C.I. is a member of Circulation Journal's Editorial Team.

\section{IRB Information}

Data collection, analysis, and reporting were approved by the National Cerebral and Cardiovascular Research Center's Institutional Review Board (Reference number: M30-026, current approval date: March 9, 2021).

\section{References}

1. Leon MB, Smith CR, Mack M, Miller DC, Moses JW, Svensson LG, et al. Transcatheter aortic-valve implantation for aortic stenosis in patients who cannot undergo surgery. $N$ Engl $J$ Med 2010; 363: 1597-1607.

2. Smith CR, Leon MB, Mack MJ, Miller DC, Moses JW, Svensson $\mathrm{LG}$, et al. Transcatheter versus surgical aortic-valve replacement in high-risk patients. $N$ Engl J Med 2011; 364: 2187-2198.

3. Popma JJ, Adams DH, Reardon MJ, Yakubov SJ, Kleiman NS, Heimansohn D, et al. Transcatheter aortic valve replacement using a self-expanding bioprosthesis in patients with severe aortic stenosis at extreme risk for surgery. J Am Coll Cardiol 2014; 63: $1972-1981$.

4. Mack MJ, Leon MB, Smith CR, Miller DC, Moses JW, Tuzcu EM, et al. 5-year outcomes of transcatheter aortic valve replacement or surgical aortic valve replacement for high surgical risk patients with aortic stenosis (PARTNER 1): A randomised controlled trial. Lancet 2015; 385: 2477-2484.

5. Leon MB, Smith CR, Mack MJ, Makkar RR, Svensson LG, Kodali SK, et al. Transcatheter or surgical aortic-valve replacement in intermediate-risk patients. $N$ Engl J Med 2016; 374: $1609-1620$.

6. Thourani VH, Kodali S, Makkar RR, Herrmann HC, Williams $\mathrm{M}$, Babaliaros V, et al. Transcatheter aortic valve replacement versus surgical valve replacement in intermediate-risk patients: A propensity score analysis. Lancet 2016; 387: 2218-2225.
7. Mack MJ, Leon MB, Thourani VH, Makkar R, Kodali SK, Russo $\mathrm{M}$, et al. Transcatheter aortic-valve replacement with a balloon-expandable valve in low-risk patients. $N$ Engl $J$ Med 2019; 380: 1695-1705.

8. Popma JJ, Deeb GM, Yakubov SJ, Mumtaz M, Gada H, O'Hair $\mathrm{D}$, et al. Transcatheter aortic-valve replacement with a selfexpanding valve in low-risk patients. N Engl J Med 2019; 380: $1706-1715$.

9. Pibarot P, Salaun E, Dahou A, Avenatti E, Guzzetti E, Annabi MS, et al. Echocardiographic results of transcatheter versus surgical aortic valve replacement in low-risk patients: The PARTNER 3 Trial. Circulation 2020; 141: 1527-1537.

10. Siontis GCM, Overtchouk P, Cahill TJ, Modine T, Prendergast $\mathrm{B}$, Praz F, et al. Transcatheter aortic valve implantation vs. surgical aortic valve replacement for treatment of symptomatic severe aortic stenosis: An updated meta-analysis. Eur Heart J 2019; 40: 3143-3153.

11. Carroll JD, Mack MJ, Vemulapalli S, Herrmann HC, Gleason TG, Hanzel G, et al. STS-ACC TVT registry of transcatheter aortic valve replacement. J Am Coll Cardiol 2020; 76: 2492-2516.

12. Auffret V, Lefevre T, Van Belle E, Eltchaninoff H, Iung B, Koning $\mathrm{R}$, et al. Temporal trends in transcatheter aortic valve replacement in France: FRANCE 2 to FRANCE TAVI. $J$ Am Coll Cardiol 2017; 70: 42-55.

13. Grover FL, Vemulapalli S, Carroll JD, Edwards FH, Mack MJ, Thourani VH, et al. 2016 annual report of the Society of Thoracic Surgeons/American College of Cardiology Transcatheter Valve Therapy Registry. J Am Coll Cardiol 2017; 69: 1215-1230.

14. Fröhlich GM, Baxter PD, Malkin CJ, Scott DJ, Moat NE, HildickSmith D, et al. Comparative survival after transapical, direct aortic, and subclavian transcatheter aortic valve implantation (data from the UK TAVI registry). Am J Cardiol 2015; 116: 1555-1559.

15. Dahle TG, Kaneko T, McCabe JM. Outcomes following subclavian and axillary artery access for transcatheter aortic valve replacement: Society of the Thoracic Surgeons/American College of Cardiology TVT Registry Report. JACC Cardiovasc Interv 2019; 12: 662-669.

16. Allen KB, Chhatriwalla AK, Saxon J, Hermiller J, Heimansohn $\mathrm{D}$, Moainie S, et al. Transcarotid versus transthoracic access for transcatheter aortic valve replacement: A propensity-matched analysis. J Thorac Cardiovasc Surg, doi:10.1016/j/jtcvs.2020.09.133.

17. Chamandi C, Abi-Akar R, Rodes-Cabau J, Blanchard D, Dumont E, Spaulding C, et al. Transcarotid compared with other alternative access routes for transcatheter aortic valve replacement. Circ Cardiovasc Interv 2018; 11: e006388.

18. Otto CM, Nishimura RA, Bonow RO, Carabello BA, Erwin JP 3rd, Gentile F, et al. 2020 ACC/AHA guideline for the management of patients with valvular heart disease: A report of the American College of Cardiology/American Heart Association Joint Committee on Clinical Practice Guidelines. Circulation 2021; 143: e72-e227.

19. Kobayashi J, Shimahara Y, Fujita T, Kanzaki H, Amaki M, Hata $\mathrm{H}$, et al. Early results of simultaneous transaortic transcatheter aortic valve implantation and total arterial off-pump coronary artery revascularization in high-risk patients. Circ $J$ 2016; 80: 1946-1950.

20. Généreux P, Piazza N, Alu MC, Nazif T, Hahn RT, Pibarot P, et al. Valve Academic Research Consortium 3: Updated endpoint definitions for aortic valve clinical research. $J$ Am Coll Cardiol 2021; 77: 2717-2746.

21. Dunne B, Tan D, Chu D, Yau V, Xiao J, Ho KM et al. Transapical versus transaortic transcatheter aortic valve implantation: A systematic review. Ann Thorac Surg 2015; 100: 354-361.

22. Junquera L, Kalavrouziotis D, Dumont E, Rodés-Cabau J, Mohammadi S. Paradigm shifts in alternative access for transcatheter aortic valve replacement: An update. $J$ Thorac Cardiovasc Surg, doi:10.1016/j.jtcvs.2021.04.075.

23. Thourani VH, Jensen HA, Babaliaros V, Suri R, Vemulapalli S, Dai D, et al. Transapical and transaortic transcatheter aortic valve replacement in the United States. Ann Thorac Surg 2015; 100: $1718-1727$.

24. Ribeiro HB, Dahou A, Urena M, Carrasco JL, Mohammadi S, Doyle D, et al. Myocardial injury after transaortic versus transapical transcatheter aortic valve replacement. Ann Thorac Surg 2015; 99: 2001-2009.

25. Elmariah S, Fearon WF, Inglessis I, Vlahakes GJ, Lindman BR, Alu MC, et al. Transapical transcatheter aortic valve replacement is associated with increased cardiac mortality in patients with left ventricular dysfunction: Insights from the PARTNER I Trial. JACC Cardiovasc Interv 2017; 10: 2414-2422. 
26. Al-Attar N, Ghodbane W, Himbert D, Rau C, Raffoul R, Messika-Zeitoun D, et al. Unexpected complications of transapical aortic valve implantation. Ann Thorac Surg 2009; 88: 90-94.

27. Pasic M, Unbehaun A, Dreysse S, Drews T, Buz S, Kukucha M, et al. Transapical aortic valve implantation in 175 consecutive patients: Excellent outcome in very high-risk patients. J Am Coll Cardiol 2010; 56: 813-820.

28. Wong DR, Ye J, Cheung A, Webb JG, Carere RG, Lichtenstein SV. Technical considerations to avoid pitfalls during transapical aortic valve implantation. J Thorac Cardiovasc Surg 2010; 140: 196-202.

29. Romano M, Daprati A, Saitto G, Tizzano F, Le Houérou D, Donzeau-Gouge P, et al. Safety and effectiveness of a transaortic approach for TAVI: Procedural and midterm outcomes of 265 consecutive patients in a single centre. Interact Cardiovasc Thorac Surg 2020; 30: 400-407.

30. Rodes-Cabau J, Gutierrez M, Bagur R, De Larochelliere R,
Doyle D, Cote M, et al. Incidence, predictive factors, and prognostic value of myocardial injury following uncomplicated transcatheter aortic valve implantation. J Am Coll Cardiol 2011; 57: $1988-1999$.

31. Bapat V, Frank D, Cocchieri R, Jagielak D, Bonaros N, Marco A, et al. Transcatheter aortic valve replacement using transaortic access: Experience from the multicenter, multinational, prospective ROUTE Registry. Cardiovasc Interv 2016; 9: 1815-1822.

\section{Supplementary Files}

Supplementary Movie. Technique of transaortic transcatheter aortic valve replacement via right mini-thoracotomy at the second intercostal space.

Please find supplementary file(s);

http://dx.doi.org/10.1253/circj.CJ-21-0877 